Cite this: Org. Chem. Front., 2014, 1 , 532

Received 5th March 2014, Accepted 18th April 2014 DOI: $10.1039 / c 4 q 000064 a$ rsc.li/frontiers-organic

\section{Self-sorting of crown ether/secondary ammonium ion hetero-[c2]daisy chain pseudorotaxanes $\uparrow$}

\author{
Bo Zheng, ${ }^{a}$ Fabian Klautzsch, ${ }^{\mathrm{b}}$ Min Xue, ${ }^{\mathrm{a}}$ Feihe Huang ${ }^{\mathrm{a}}$ and Christoph A. Schalley*b
}

Four monomeric building blocks equipped with one crown ether and one secondary ammonium ion are synthesized and studied with respect to their ability to form daisy chain dimers. Two crown ethers with different cavity sizes - i.e. [21]crown-7 and [24]crown-8 - and two ammonium ions substituted with either a thin alkyl group or a more bulky benzyl group are used as the binding motifs. Self-sorting behaviour can be expected as the [21]crown-7/alkyl ammonium and [24]crown-8/benzyl ammonium binding motifs are orthogonal. Three homodimers are characterized by NMR, X-ray crystallography and ESI mass spectrometry. They are recognizable by the presence of signals for diastereotopic protons in the ${ }^{1} \mathrm{H}$ NMR spectra. The formation of hetero-[c2] daisy chain dimers can be monitored by NMR spectroscopy and ESI mass spectrometry and show the expected self-sorting behaviour.

\section{Introduction}

Nature efficiently and successfully assembles intricate and highly complex architectures, ${ }^{1}$ in which high-fidelity selfsorting $^{2}$ is ubiquitous as the basis of the building blocks' cooperative functional interplay. Many supramolecular chemists have recently constructed synthetic self-sorting systems with orthogonal binding motifs fabricated on the basis of hydrogen bonding, ${ }^{3}$ metal-ligand interactions, ${ }^{4} \pi-\pi$-stacking ${ }^{5}$ or solvophobic effects. ${ }^{6}$ A number of different factors, among them the orthogonality of the recognition motifs, size, shape, thermodynamic and kinetic binding parameters, stoichiometry and concentration define the molecular codes and are responsible for self-recognition (narcissistic self-sorting) or self-discrimination (social self-sorting). ${ }^{2,5 a, 7}$

Recently, we have applied the concepts of social self-sorting to pseudorotaxane $e^{8}$ assemblies and supramolecular pseudorotaxane polymers based on the crown ether/secondary ammonium ion binding motifs. ${ }^{9}$ Benzo[21]crown-7 $\mathbf{C 7}$ and dibenzo[24]crown-8 C8 (Fig. 1) have two different cavity sizes and their pseudorotaxane binding motifs with secondary ammonium ions can be made orthogonal by using either

\footnotetext{
${ }^{a}$ State Key Laboratory of Chemical Engineering, Department of Chemistry, Zhejiang University, Hangzhou, Zhejiang 310027, China.E-mail: fhuang@zju.edu.cn ${ }^{b}$ Institut für Chemie und Biochemie, Freie Universität Berlin, Takustr. 3, 14195 Berlin, Germany.E-mail: c.schalley@fu-berlin.de

$\dagger$ Electronic supplementary information (ESI) available: Additional NMR and MS data, ellipsoid plots of new crystal structures. CCDC 952285 and 981643 . For ESI and crystallographic data in CIF or other electronic format see DOI: 10.1039/ c4qo00064a
}
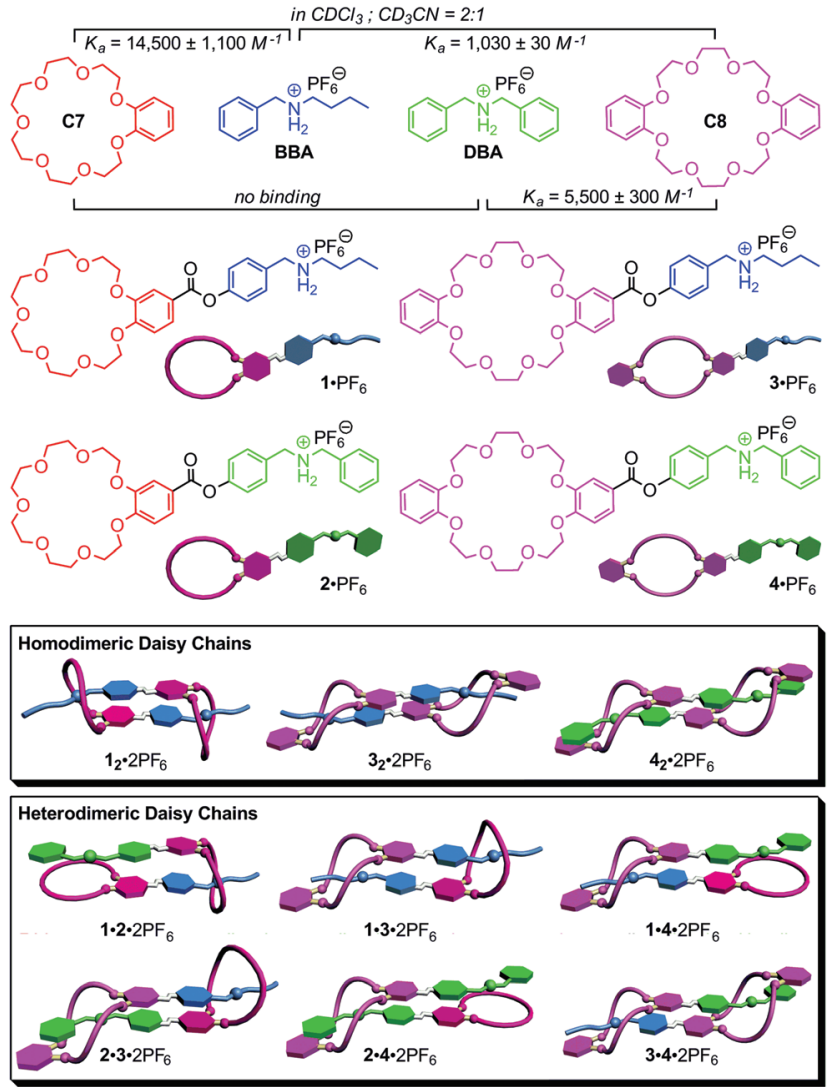

Fig. 1 Top: Structures and binding data of building blocks C7, C8, BBA and DBA. Centre: Monomers 1.PF 6 -4.PF . Bottom: Cartoons representing all possible homo- and heterodimeric daisy chains. Note that dimer $2_{2} \cdot 2 \mathrm{PF}_{6}$ does not form and 1.2.2PF 6 and 1.4.2PF 6 cannot ring-close. 
benzyl- $n$-butyl ammonium BBA with one thin alkyl ammonium or dibenzyl ammonium DBA with two more bulky benzyl ammonium stopper groups. As the benzyl stopper is too large to penetrate $\mathbf{C 7}$, only three host-guest complexes BBA.C7, BBA.C8 and DBA.C8 can form. Fig. 1 summarizes the binding constants for these pairs in a $\mathrm{CDCl}_{3}-\mathrm{CH}_{3} \mathrm{CN}(2: 1)$ solvent mixture. When the feed ratio is controlled and all four components are mixed in equimolecular amounts, self-sorting is obtained, because the DBA guest cation consumes all C8 host molecules while only $\mathbf{C} 7$ binds BBA. But even, when feed ratio is not perfectly matched, this self-sorting behaviour is expected to occur, because the BBA.C7 and DBA.C8 pairs exhibit the two highest binding constants of $14500 \mathrm{M}^{-1}$ and $5500 \mathrm{M}^{-1}$, respectively, among the three possible pseudorotaxanes. ${ }^{10}$ Consequently, the resulting self-sorting is driven kinetically (stopper sizes) as well as thermodynamically (binding constants) into the same direction.

[c2]Daisy chains are cyclic interwoven oligo- or even polymers ${ }^{11}$ that are usually constructed from AB-type plerotopic monomers equipped with two complementary binding units A (host) and B (guest). Usually, small, often dimeric macrocyclic assemblies result, because they are enthalpically (all binding sites involved in binding) as well as entropically (high particle number) favourable. Such self-complementary building blocks - when equipped with two switchable stations - are also excellent building blocks for molecular muscle-type supramolecular polymers. ${ }^{12}$ The daisy chains known so far are all constructed from identical monomers. This limits the structural diversity that can be obtained by self-assembly. In contrast, progress towards functional complexes containing different cooperating building blocks to realize high-level function would require the ability to build well-defined architectures, in which each subunit occupies a precisely controlled position. It is therefore highly desirable to provide strategies for programming different monomers into heteromeric assemblies. Self-sorting is one potential strategy in this direction.

Here, we apply the principles of social self-sorting to the construction of heterodimeric [c2]daisy chains. The aim of the present study is to investigate their self-sorting behaviour and to extend the scope of the self-assembly of hierarchical heteromeric assemblies. The investigation of heteromeric assemblies helps understand self-sorting better and will contribute to paving a way to build well-defined assemblies that carry cooperating groups for implementing function. Four different, yet structurally quite similar monomers $\mathbf{1} \cdot \mathrm{PF}_{6}-\mathbf{4} \cdot \mathrm{PF}_{6}$ were designed (Fig. 1, centre) based on the two different crown ethers C7 and C8 and two different secondary ammonium ions BBA and DBA. In order to obtain these four AB-type monomers, the two binding sites - one crown ether and one ammonium ion - are connected through ester linkages as reported earlier for $\mathbf{1} \cdot \mathrm{PF}_{6} \cdot{ }^{13}$

Based on the self-sorting behaviour of C7, C8, BBA and DBA, one would arrive at the following expectations (Fig. 1, bottom). As $2 \cdot \mathrm{PF}_{6}$ is not self-complementary due to the combination of the larger benzyl stopper with smaller crown, this monomer is predicted not to dimerize. In solutions of the pure monomers, three homodimers should therefore form under the appropriate conditions: $\mathbf{1}_{2} \cdot 2 \mathrm{PF}_{6}, \mathbf{3}_{2} \cdot 2 \mathrm{PF}_{6}$ and $\mathbf{4}_{2} \cdot 2 \mathrm{PF}_{6}$. A $1: 1$ mixture of $2 \cdot \mathrm{PF}_{6}$ and $3 \cdot \mathrm{PF}_{6}$ should convert fully into the heterodimer $\mathbf{2} \cdot \mathbf{3} \cdot 2 \mathrm{PF}_{6}$ (perfect self-sorting), because the two building blocks are matching each other. Binding can only involve all binding sites, when the heterodimeric daisy chain forms exclusively. Otherwise, monomeric $2 \cdot \mathrm{PF}_{6}$ would remain with unsaturated binding sites along with the $3_{2} \cdot 2 \mathrm{PF}_{6}$ homodimer. For a $1: 1$ mixture of $1 \cdot \mathrm{PF}_{6}$ and $3 \cdot \mathrm{PF}_{6}$, one predicts a statistical $1: 2: 1$ mixture of $\mathbf{1}_{2} \cdot 2 \mathrm{PF}_{6}, \mathbf{1} \cdot 3 \cdot 2 \mathrm{PF}_{6}$ and $3_{2} \cdot 2 \mathrm{PF}_{6}$ as the final result of the assembly, since both homodimers as well as the heterodimer can easily form and their equilibration should be more or less thermoneutral. For all other combinations, no significant heterodimer formation is expected, as the heterodimers $\mathbf{1 \cdot 2} \cdot 2 \mathrm{PF}_{6}, \mathbf{1} \cdot \mathbf{4} \cdot 2 \mathrm{PF}_{6}$ and $\mathbf{2 \cdot 4} \cdot 2 \mathrm{PF}_{6}$ can merely form singly threaded heterodimeric daisy chains. The formation of heterodimers would thus lead to unsaturated binding sites and is then less favourable as the mixture of both homodimers.

\section{Results and discussion}

\section{Monomer synthesis and characterisation}

The synthesis of $2 \cdot \mathrm{PF}_{6}-\mathbf{4} \cdot \mathrm{PF}_{6}$ follows the previously reported preparation of $\mathbf{1} \cdot \mathrm{PF}_{6}$ (Fig. 2). ${ }^{13,14}$ Briefly, the acid derivatives of

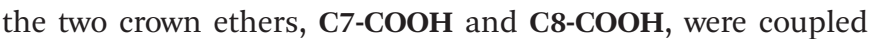
with Boc-protected derivatives 5 and $\mathbf{6}$ of DBA and BBA, respectively. After de-protection and ion exchange, the desired target compounds $\mathbf{1} \cdot \mathrm{PF}_{6}-\mathbf{4} \cdot \mathrm{PF}_{6}$ were obtained.

In order to characterize the samples as monomers, NMR spectra were recorded in DMSO- $d_{6}$ (ESI $\dagger$ ), in which only one set of signals is observed. Although the substitution of the crown ethers' benzo moieties with the ester group renders all methylene groups of the crowns non-equivalent, they are somewhat broadened as they are pairwise almost isochronous and thus closely overlapping mostly depending on the distance to the aromatic ring.

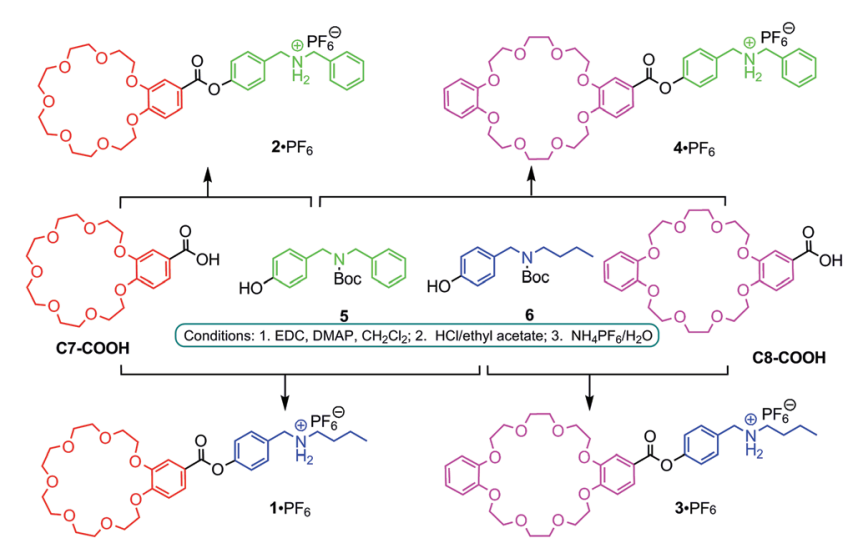

Fig. 2 Synthesis of monomers 1.PF $6-4 \cdot \mathrm{PF}_{6}$. (EDC = 1-ethyl-3(3-dimethylaminopropyl) carbodiimide hydrochloride; $\mathrm{DMAP}=4$ dimethylaminopyridine). 


\section{Homodimers $\mathbf{1}_{2} \cdot 2 \mathrm{PF}_{6}, 3_{2} \cdot 2 \mathrm{PF}_{6}$ and $\mathbf{4}_{2} \cdot 2 \mathrm{PF}_{6}$}

Before discussing the formation of homodimers, a brief comment on the chirality features of the daisy chains may be indicated. All four monomers are achiral compounds. Upon threading an unsymmetrical axle through each of the crown ethers, chiral complexes are possible. The ester groups define directionality around the crown ether; the axle defines a direction perpendicular to the crown ether plane. Consequently, such a complex exhibits planar chirality. This is certainly true for all heterodimeric [c2]daisy chains, which may thus form four different stereoisomers that are in equilibrium with each other. However, one should be aware of the fact that homodimeric [c2]daisy chains may exist as a pair of enantiomers plus one achiral meso-diastereomer bearing a centre of inversion so that only three stereoisomers can exist in equilibrium here.

In less competitive solvents, three of the monomers, 1. $\mathrm{PF}_{6}{ }^{13}{ }^{13} 3 \cdot \mathrm{PF}_{6}$ and $4 \cdot \mathrm{PF}_{6}$, are expected to form homodimers. Indeed, the ${ }^{1} \mathrm{H}$ NMR spectra of these three compounds in a $2: 1$ mixture of chloroform and acetonitrile (Fig. 3) are much more complex than those in DMSO, while $2 \cdot \mathrm{PF}_{6}$ retains its simplicity also in this less competitive solvent mixture. The increased complexity is caused by two effects: threading on one hand leads to more significant differences in the environments of those crown ether methylene groups that overlap in the spectra of the monomers. In addition, the two faces of the crown ethers become different upon threading of the axle. Thus, at least some of the methylene groups give rise to separate signals for the two protons. Even with the help of $2 \mathrm{D}$ spectra, a complete assignment of all signals is difficult as many of them still strongly overlap (ESI $\dagger$ ). The best signal separation is found for $\mathbf{4}_{2} \cdot 2 \mathrm{PF}_{6}$ (Fig. 3) so that we can clearly identify two pairs of diastereomers (one from the phenylmethyl proton and one from the crown methylene) and other diastereotopic signals of crown $\mathrm{CH}_{2}$ groups here (ESI $\dagger$ ). Also, typical complexation-induced shifts indicate the formation of daisy chain dimers: In particular, the aromatic protons $\mathrm{H}^{\mathrm{a}}$ and $\mathrm{H}^{\mathrm{c}}$ of $\mathbf{1}_{2} \cdot \mathrm{PF}_{6}, \mathbf{3}_{2} \cdot \mathrm{PF}_{6}$ and $\mathbf{4}_{2} \cdot \mathrm{PF}_{6}$ are shifted up-field relative to

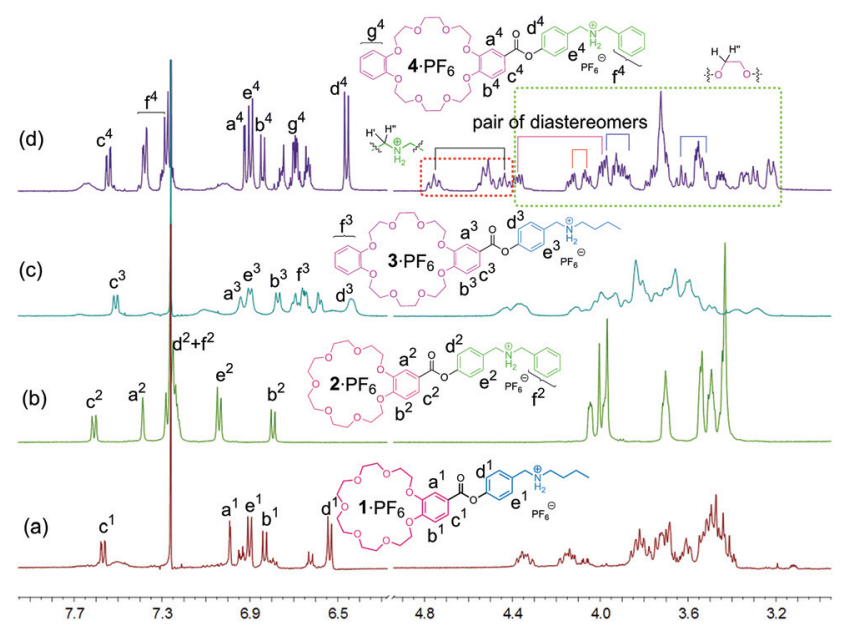

Fig. 3 Partial ${ }^{1} \mathrm{H}$ NMR spectra $\left(500 \mathrm{MHz}, \mathrm{CDCl}_{3}-\mathrm{CD}_{3} \mathrm{CN} \quad(2: 1)\right.$ $10.0 \mathrm{mM}, 298 \mathrm{~K}$ ) of (a) $1_{2} \cdot 2 \mathrm{PF}_{6}$ (b) $2 \cdot \mathrm{PF}_{6}$, (c) $3_{2} \cdot 2 \mathrm{PF}_{6}$ and (d) $4_{2} \cdot 2 \mathrm{PF}_{6}$. those of the free monomer in DMSO- $d_{6}$, the monomer form of $2 \cdot \mathrm{PF}_{6}$ in $\mathrm{CDCl}_{3}-\mathrm{CD}_{3} \mathrm{CN}(2: 1)$ or the potassium complex (vide infra), with the most significant shift observed for $\mathrm{H}^{\mathrm{a}}$. This indicates - irrespective of the reference system chosen - the up-field shift to be due to the anisotropy effect of stacked aromatic rings which are only present in the daisy chain dimers, but do not exist in the monomers. Together with the observation of intense signals for the homodimers in the ESI mass spectra, the drastic changes in the ${ }^{1} \mathrm{H}$ NMR spectra for $\mathbf{1} \cdot \mathrm{PF}_{6}$, $3 \cdot \mathrm{PF}_{6}$ and $\mathbf{4} \cdot \mathrm{PF}_{6}$ and the absence of similar changes for $2 \cdot \mathrm{PF}_{6}$ clearly indicate the formation of the expected homodimers. Even though thermodynamically controlled macrocyclisations can give rise to larger cyclic oligomers, ${ }^{15}$ no larger complexes than dimers were detected in the mass spectra so that we rule out significant contributions from larger oligomers to the equilibrium situation.

Another piece of evidence for the formation of homodimers is their switchability with a competitive guest. When $\mathrm{KPF}_{6}$ is added to the NMR solutions of the three homodimers (ESI $\dagger$ ), the complex NMR spectra return into much simpler ones that again show only one set of signals. These signals of the potassium complex are shifted only very slightly relative to the uncomplexed monomer as demonstrated for example for $2 \cdot \mathrm{PF}_{6}$ (ESI $\dagger$ ).

Although all attempts to crystallize the heterodimers under study failed unfortunately, single crystals of homodimers $3_{2} \cdot 2 \mathrm{PF}_{6}$ and $\mathbf{4}_{2} \cdot 2 \mathrm{PF}_{6}$ were obtained. These solid state structures are shown in Fig. 4a, c and e together with the previously reported crystal structure of $\mathbf{1}_{2} \cdot 2 \mathrm{PF}_{6},{ }^{13}$ which is added to the figure to facilitate direct comparison. It is clear that in the crystal structures all three homodimers are doubly-threaded head-to-tail daisy chains. The ammonium ions are positioned inside the cavities of the crown ethers by multiple $\mathrm{N}-\mathrm{H} \cdots \mathrm{O}$ and $\mathrm{C}-\mathrm{H} \cdots \mathrm{O}$ hydrogen bonds. Table 1 summarizes the hydrogen bonding distances and angles for $\mathrm{N}-\mathrm{H} \cdots \mathrm{O}$ and $\mathrm{C}-\mathrm{H} \cdots \mathrm{O}$ hydrogen bonds which are in the ranges expected for crown ether/ammonium binding motifs. Apparently, the formation of dimers is also supported by face-to-face $\pi$-stacking interaction (a)

(c)
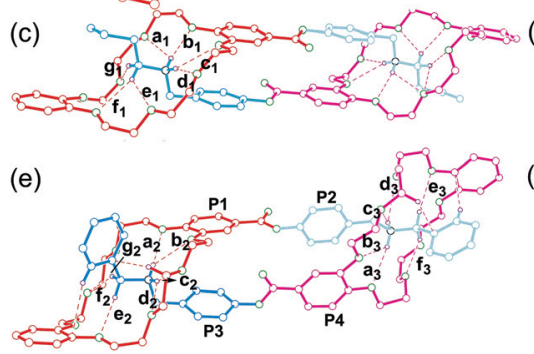

(b)

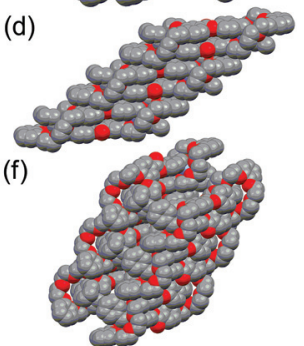

Fig. 4 Left: Ball-stick views of the $X$-ray structures of (a) $1_{2} \cdot 2 \mathrm{PF}_{6}$, (c) $3_{2} \cdot 2 \mathrm{PF}_{6}$ and (e) $4_{2} \cdot 2 \mathrm{PF}_{6} \cdot \mathrm{PF}_{6}{ }^{-}$counterions and hydrogen atoms except the ones involved in hydrogen bonding are omitted for clarity. Right: Space-filling representations of the packing of (b) $1_{2} \cdot 2 \mathrm{PF}_{6}$, (d) $3_{2} \cdot 2 \mathrm{PF}_{6}$ and (f) $4_{2} \cdot 2 P_{6}$. 
Table $1 \mathrm{C}-\mathrm{H} \cdots \mathrm{O}$ and $\mathrm{N}-\mathrm{H} \cdots \mathrm{O}$ hydrogen-bonding parameters: $\mathrm{H} \cdots \mathrm{O}$, $\mathrm{C} \cdots \mathrm{O}$, and $\mathrm{N} \cdots \mathrm{O}$ distances are given in $\AA, \mathrm{C}-\mathrm{H} \cdots \mathrm{O}$ and $\mathrm{N}-\mathrm{H} \cdots \mathrm{O}$ angles in degrees: for comparison, the previously published crystal structure data of $1_{2} \cdot 2 \mathrm{PF}_{6}{ }^{13}$ is included. Labels $\mathrm{a}_{n}-\mathrm{i}_{n}$ refer to the bond labels in Fig. 4

\begin{tabular}{|c|c|c|c|c|c|}
\hline & & $\begin{array}{l}\mathbf{1}_{2} \cdot 2 \mathrm{PF}_{6} \\
(\mathbf{a}-\mathbf{i})\end{array}$ & $\begin{array}{l}\mathbf{3}_{2} \cdot 2 \mathrm{PF}_{6} \\
\left(\mathbf{a}_{1}-\mathbf{g}_{1}\right)\end{array}$ & $\begin{array}{l}\mathbf{4}_{2} \cdot 2 \mathrm{PF}_{6} \\
\left(\mathbf{a}_{2}-\mathbf{g}_{2}\right)\end{array}$ & $\begin{array}{l}\mathbf{4}_{2} \cdot 2 \mathrm{PF}_{6} \\
\left(\mathbf{a}_{3}-\mathbf{f}_{3}\right)\end{array}$ \\
\hline \multirow[t]{3}{*}{$\mathbf{a}$} & $d_{\mathrm{H} \cdots \mathrm{O}}$ & $2.46(3)$ & $2.49(5)$ & $2.32(4)$ & $2.40(8)$ \\
\hline & $d_{\mathrm{N} \cdots \mathrm{O}}$ & $3.12(5)$ & $3.20(2)$ & $3.14(5)$ & $3.32(1)$ \\
\hline & Angle & $130.6(4)$ & $129.4(6)$ & $139.7(6)$ & $170.7(2)$ \\
\hline \multirow[t]{3}{*}{ b } & $d_{\mathrm{H} \cdots \mathrm{O}}$ & $2.16(6)$ & $2.29(0)$ & $2.56(5)$ & $2.58(7)$ \\
\hline & $d_{\mathrm{N} \cdots \mathrm{O}}$ & $2.98(3)$ & $3.14(0)$ & $3.47(1)$ & $3.11(1)$ \\
\hline & Angle & $150.5(7)$ & $153.3(8)$ & $168.4(4)$ & $116.6(7)$ \\
\hline \multirow[t]{3}{*}{ c } & $d_{\mathrm{H} \cdots \mathrm{O}}$ & $2.25(3)$ & $2.40(2)$ & $2.46(9)$ & $2.05(3)$ \\
\hline & $d_{\mathrm{N} \cdots \mathrm{O}}$ & $2.91(2)$ & $3.04(0)$ & $3.13(1)$ & $2.96(2)$ \\
\hline & Angle & $129.7(6)$ & $126.5(4)$ & $129.0(0)$ & $169.6(7)$ \\
\hline \multirow[t]{3}{*}{ d } & $d_{\mathrm{H} \cdots \mathrm{O}}$ & $2.11(2)$ & $1.99(6)$ & $2.05(0)$ & $2.56(6)$ \\
\hline & $d_{\mathrm{N} \cdots \mathrm{O}}$ & $2.91(6)$ & $2.86(5)$ & $2.91(7)$ & $3.11(8)$ \\
\hline & Angle & $148.2(0)$ & $157.0(0)$ & $156.9(2)$ & $119.0(4)$ \\
\hline \multirow[t]{3}{*}{$\mathbf{e}$} & $d_{\mathrm{H} \cdots \mathrm{O}}$ & $2.61(4)$ & $2.64(5)$ & $2.33(8)$ & $2.49(9)$ \\
\hline & $d_{\mathrm{C} \cdots \mathrm{O}}$ & $3.39(7)$ & $3.45(6)$ & $2.97(5)$ & $3.48(1)$ \\
\hline & Angle & $138.0(0)$ & $139.0(5)$ & $126.2(6)$ & $171.0(6)$ \\
\hline \multirow[t]{3}{*}{ f } & $d_{\mathrm{H} \cdots \mathrm{O}}$ & $2.29(5)$ & $2.56(0)$ & $2.51(5)$ & $2.35(6)$ \\
\hline & $d_{\mathrm{C} \cdots \mathrm{O}}$ & $3.18(8)$ & $3.47(1)$ & $3.48(7)$ & $3.13(7)$ \\
\hline & Angle & $152.7(0)$ & $152.8(6)$ & $167.0(6)$ & 135.1(1) \\
\hline \multirow[t]{3}{*}{ g } & $d_{\mathrm{H} \cdots \mathrm{O}}$ & 2.71(1) & $2.62(4)$ & $2.55(1)$ & \\
\hline & $d_{\mathrm{C} \cdots \mathrm{O}}$ & $3.15(9)$ & $3.59(8)$ & $3.43(0)$ & \\
\hline & Angle & $108.7(2)$ & $167.7(6)$ & $147.9(3)$ & \\
\hline \multirow[t]{3}{*}{ h } & $d_{\mathrm{H} \cdots \mathrm{O}}$ & $2.64(2)$ & & & \\
\hline & $d_{\mathrm{C} \cdots \mathrm{O}}$ & $3.49(9)$ & & & \\
\hline & Angle & $147.4(9)$ & & & \\
\hline \multirow[t]{3}{*}{ i } & $d_{\mathrm{H} \cdots \mathrm{O}}$ & $2.40(5)$ & & & \\
\hline & $d_{\mathrm{C} \cdots \mathrm{O}}$ & $3.28(0)$ & & & \\
\hline & Angle & $149.7(6)$ & & & \\
\hline
\end{tabular}

between the aromatic ring of the host moiety and the phenyl ring of the ammonium salt unit. The centroid-centroid distances are $3.64 \AA$ in $\mathbf{1}_{2} \cdot 2 \mathrm{PF}_{6}$ and $3.68 \AA$ in $3_{2} \cdot 2 \mathrm{PF}_{6}$. The structure of $\mathbf{4}_{2} \cdot 2 \mathrm{PF}_{6}$ differs in three respects from the other two: (i) although both monomers in the homodimer are identical, its crystal structure reveals two different binding motifs with different hydrogen bonding parameters realized - an effect that is likely due to packing effects. (ii) The aromatic rings are not aligned in a face-to-face fashion, but are twisted into arrangements with inclinations of $70.1^{\circ}$ and $82.2^{\circ}$ between the two planes of adjacent aromatic rings. (iii) Both ester carbonyl groups point in the same direction, while the other two homodimers have ester groups that point in opposite directions. Consequently, $\mathbf{1}_{2} \cdot 2 \mathrm{PF}_{6}$ and $\mathbf{3}_{2} \cdot 2 \mathrm{PF}_{6}$ bear a centre of inversion and realize the above-mentioned meso-forms, while no centre of inversion exists in the crystal of $\mathbf{4}_{2} \cdot 2 \mathrm{PF}_{6}$, which thus is present as a chiral complex. The daisy chain homodimers pack in the crystal to yield infinite supramolecular tapes driven by face-to-face $\pi$-stacking interactions (Fig. $4 \mathrm{~b}, \mathrm{~d}$ and f). In the crystal structure of $\mathbf{4}_{2} \cdot 2 \mathrm{PF}_{6}$, homochiral tapes each containing only one of the two enantiomeric assemblies alternate.

\section{Mass spectrometry as a method to detect self-sorting}

As discussed above, already the NMR spectra of the homodimers are rather complicated and difficult to interpret. If one attempts to analyse the generation of heterodimers, even more complicated spectra are expected to be observed. A detailed understanding, in particular a quantification of the contributions of homo- and heterodimers in solution will therefore not be straightforward by NMR spectroscopy. Crystallography neither provides a picture of the solution situation, even if suitable crystals could be grown, as solution equilibria may be shifted significantly upon crystallization. Therefore, ESI mass spectrometry appears to be a favourable tool to at least semi-quantitatively analyse the self-sorting behaviour of the daisy chains under study. A number of earlier studies on the assembly of other self-sorting pseudorotaxanes support this. $^{3 d, e, 6 b, 9 b, c, e, f}$

Four points, however, may limit the scope of the analysis and should be considered in the interpretation of the data: (i) doubly charged homodimers will appear at the same $\mathrm{m} / \mathrm{z}$ as singly charged monomers. They can however be easily distinguished as the peak spacing in the isotope patterns is 0.5 for the dicationic dimer and 1 for the singly charged monomer. Isotope pattern deconvolution has therefore been performed for all samples under study here. (ii) The sample solution concentrations used in ESI mass spectrometry are considerably lower than NMR concentrations. This may lead to a shift of the monomer-dimer equilibria towards the monomers so that the monomers may appear more prominently than expected from solution experiments. Furthermore, the monomers may form from the dimers, if the ions dissociate in part during ionization. Consequently, some contribution from monomeric species is expected to be observed. In the experiments reported here, sample concentrations were $100 \mu \mathrm{M}$ in each monomer to reduce the concentration difference of NMR and MS samples as much as possible. (iii) Ion intensities do not necessarily directly reflect solution concentrations. The efficiencies with which the ions form during the electrospray process depend significantly on the desolvation energies ${ }^{16}$ which may vary for different structures. Although the differences in the so-called ESI response factors are often not very large for structurally similar ions, exceptions exist. (iv) Non-specific binding often occurs in ESI mass spectrometry. If it is prominent, it may blur the analysis of self-sorting, because non-specific complexes will not exhibit self-sorting and superimpose the true distribution of self-sorted complexes. In our study, we chose ionization conditions such that non-specific binding is minimal.

\section{The $1_{2} \cdot 2 \mathrm{PF}_{6} / \mathbf{4}_{2} \cdot 2 \mathrm{PF}_{6}(1: 1)$ and $2 \cdot \mathrm{PF}_{6} / \mathbf{4}_{2} \cdot 2 \mathrm{PF}_{6}(2: 1)$ mixtures}

When $\mathbf{1}_{2} \cdot 2 \mathrm{PF}_{6}$ and $\mathbf{4}_{2} \cdot 2 \mathrm{PF}_{6}$ are mixed in equimolar amounts, no significant change is expected to occur. Both compounds form homodimers already in the stock solutions before mixing so that all binding sites are saturated. The heterodimer instead must remain singly threaded if it forms at all as the benzyl stopper in $\mathbf{4} \cdot \mathrm{PF}_{6}$ is unable to thread through the [21]crown-7 ether in 1.PF $\mathrm{PF}_{6}$. As this situation is energetically less favourable, there is consequently no driving force for heterodimer formation.

Fig. 5a shows the corresponding ESI mass spectrum recorded after $15 \mathrm{~min}$ of equilibration. Clearly, the two homodimers are the dominating species; $\mathbf{1}_{2}{ }^{2+}$ appears with $c a$. $35 \%$, 

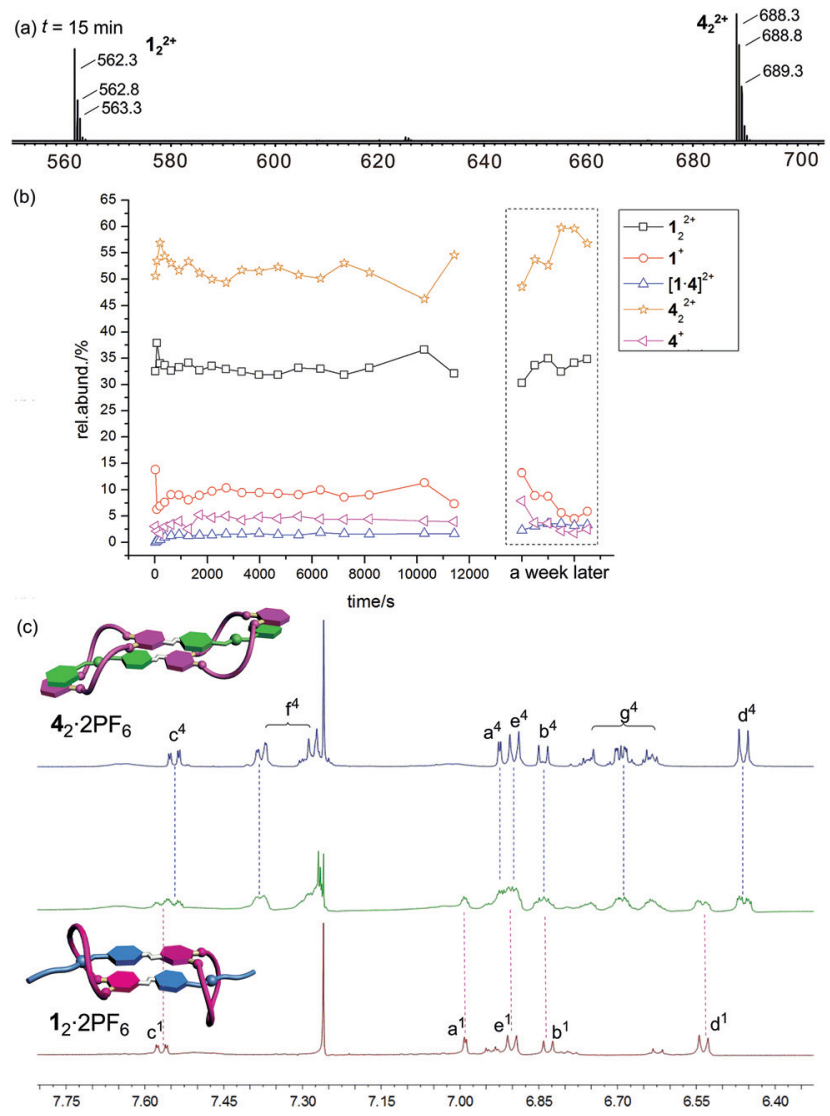

Fig. 5 (a) Partial ESI mass spectrum of a $1: 1$ mixture of $1_{2} \cdot 2 \mathrm{PF}_{6}$ and $42 \cdot 2 \mathrm{PF}_{6}\left(100 \mu \mathrm{M}\right.$ for each monomer) in $\mathrm{CHCl}_{3}-\mathrm{CH}_{3} \mathrm{CN}(2: 1)$ recorded after $15 \mathrm{~min}$ of equilibration time. (b) More spectra have been recorded after different time intervals. No change is observed even after a week. (c) Partial ${ }^{1} \mathrm{H}$ NMR spectra $\left(500 \mathrm{MHz}, \mathrm{CDCl}_{3}-\mathrm{CD}_{3} \mathrm{CN}=2: 1,10.0 \mathrm{mM}\right.$, $298 \mathrm{~K}$ ) of $1_{2} \cdot \mathrm{PF}_{6}$ (bottom row), an equimolar mixture of $1_{2} \cdot 2 \mathrm{PF}_{6}$ and $4_{2} \cdot 2 \mathrm{PF}_{6}$ (centre), and $4_{2} \cdot 2 \mathrm{PF}_{6}$ (top row).

$\mathbf{4}_{2}{ }^{2+}$ with $c a .55 \%$ intensity. The heterodimer $[\mathbf{1 \cdot 4}]^{2+}$ is always below $3 \%$. No changes are found when the sample was left to equilibrate for periods as long as a week. This result first of all confirms that heterodimer formation is unfavourable as expected. The low intensity of the heterodimer also indicates that non-specific dimerization does not play a significant role under the experimental conditions applied. The differences of the intensities of the two homodimers point to some differences in the ESI response factors. Nevertheless, a semiquantitative picture is obtained.

The mass spectrometric results are in agreement with the ${ }^{1} \mathrm{H}$ NMR spectra in Fig. 5c. Although the spectrum of the mixture is somewhat less well-resolved, it is quite clear that this spectrum is a superposition of the two spectra of the homodimers. Full spectra and ${ }^{1} \mathrm{H},{ }^{1} \mathrm{H}$ COSY data are given in the ESI. $\dagger$ In conclusion, both methods are in agreement with the hypothesis that $\mathbf{1}_{2} \cdot 2 \mathrm{PF}_{6}$ and $\mathbf{4}_{2} \cdot 2 \mathrm{PF}_{6}$ do not form heterodimers.

A similar situation is observed for the $2: 1$ mixture of $2 \cdot \mathrm{PF}_{6}$ and $\mathbf{4}_{2} \cdot 2 \mathrm{PF}_{6}$ that is equimolar in monomer concentration. The heterodimer appears in the mass spectra (ESI $\dagger$ ) below 5\% intensity accompanied mainly by $\mathbf{2}^{+}$and $\mathbf{4}_{2}{ }^{2+}$. Due to the larger structural differences between a monomer $\left(2^{+}\right)$and a dimer $\left(\mathbf{4}_{2}{ }^{2+}\right)$, larger differences in the ESI response factors can be expected. Indeed, the $\mathbf{2}^{+}$ion is much lower in intensity than the $\mathbf{4}_{2}{ }^{2+}$ dimer. When judging the intensities, it must however be taken into account that they are proportional to the charge state in Fourier-transform ion-cyclotron-resonance (FTICR) mass spectrometry. Consequently, the $\mathbf{4}_{2}{ }^{2+}$ dication intensity is two times higher than that of a singly charged cation of the same abundance. The NMR spectra (ESI $\dagger$ ) are again complex, but can be rationalized by a superposition of $2 \cdot \mathrm{PF}_{6}$ and $\mathbf{4}_{2} \cdot 2 \mathrm{PF}_{6}$.

Upon closer inspection, this result might be surprising. As $2 \cdot \mathrm{PF}_{6}$ does not form homodimers, an exchange of $2 \cdot \mathrm{PF}_{6}$ against a monomer in $\mathbf{4}_{2} \cdot 2 \mathrm{PF}_{6}$ to yield the heterodimer would result in the same number of satisfied binding sites and should thus be thermoneutral. Consequently, one might have expected more singly threaded heterodimer and an exchange equilibrium in which $2 \cdot \mathrm{PF}_{6}, \mathbf{4}_{2} \cdot 2 \mathrm{PF}_{6}$ and $\mathbf{2} \cdot \mathbf{4} \cdot 2 \mathrm{PF}_{6}$ coexist. However, a doubly threaded, divalent dimer $\mathbf{4}_{2} \cdot 2 \mathrm{PF}_{6}$ may well benefit from chelate cooperativity ${ }^{17}$ as observed recently for other divalent crown ammonium pseudorotaxanes. ${ }^{9 h}$ The open, singly threaded dimer $\mathbf{2 \cdot 4} \cdot 2 \mathrm{PF}_{6}$ does of course not profit from such a chelate cooperativity effect.

The $1_{2} \cdot 2 \mathrm{PF}_{6} / 3_{2} \cdot 2 \mathrm{PF}_{6}(1: 1)$ mixture

Mixing $\mathbf{1}_{2} \cdot 2 \mathrm{PF}_{6}$ and $\mathbf{3}_{2} \cdot 2 \mathrm{PF}_{6}$ in equimolar amounts leads indeed to the expected statistical mixture of $\mathbf{1}_{2} \cdot 2 \mathrm{PF}_{6}, \mathbf{1} \cdot 3 \cdot 2 \mathrm{PF}_{6}$, and $\mathbf{3}_{2} \cdot 2 \mathrm{PF}_{6}$ as indicated by the appearance of $\mathbf{1}_{2}{ }^{2+},[\mathbf{1} \cdot \mathbf{3}]^{2+}$ and $\mathbf{3}_{2}{ }^{2+}$ in the ESI mass spectrum of the mixture (Fig. 6a). As anticipated, the homodimer dications are superimposed by signals of monomers $\mathbf{1}^{+}$and $3^{+}$. The intensity ratio of the three dimeric dications is about $3: 8: 6\left(\mathbf{1}_{2}{ }^{2+}:[\mathbf{1} \cdot 3]^{2+}: \mathbf{3}_{2}{ }^{2+}\right)$. If one takes into account the likely differing desolvation energies, this ratio is more or less in agreement with a statistical formation of the three dimeric daisy chains.

The exchange of monomers between the two homodimers to yield the heterodimeric daisy chain is quite slow and can be followed by ESI mass spectrometry (Fig. 6b). If one takes the development of the heterodimer ion intensity as an example, one arrives at an estimate for the half-life of roughly 230 seconds. The exchange reaction thus proceeds on a minute time scale.

The ${ }^{1} \mathrm{H}$ NMR spectra are very complicated and difficult to interpret - in particular when it comes to quantification of the different dimers present in solution. However, quite clearly, the signals for $\mathrm{H}^{\mathrm{b}}$ and $\mathrm{H}^{\mathrm{c}}$ of the two compounds in the aromatic region provide evidence that the spectrum of the mixture is more than a mere superposition of the two homodimer spectra. Additional signals are observed, which together with the ESI mass spectrometric results at least provide qualitative evidence for the presence of the homo- and heterodimers in the sample solution.

\section{The $2 \cdot \mathrm{PF}_{6} / 3_{2} \cdot 2 \mathrm{PF}_{6}(2: 1)$ mixture}

Finally, the mixture of $2 \cdot \mathrm{PF}_{6} / \mathbf{3}_{2} \cdot 2 \mathrm{PF}_{6}$ (equimolar in monomer concentration) is expected to self-sort into the heterodimer 


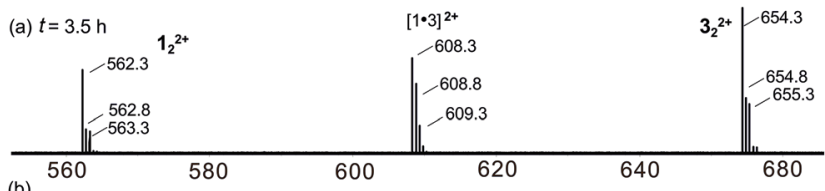

(b)

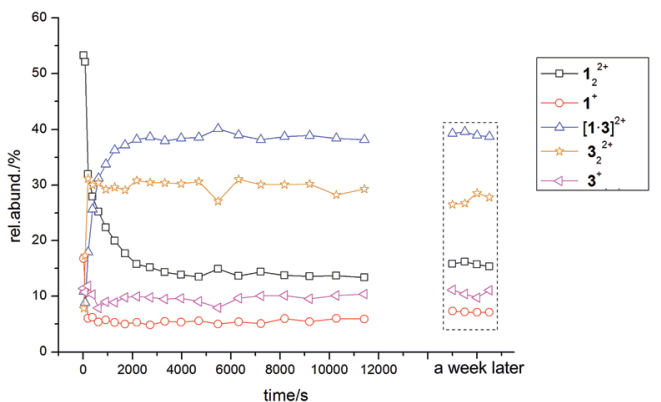

(c)

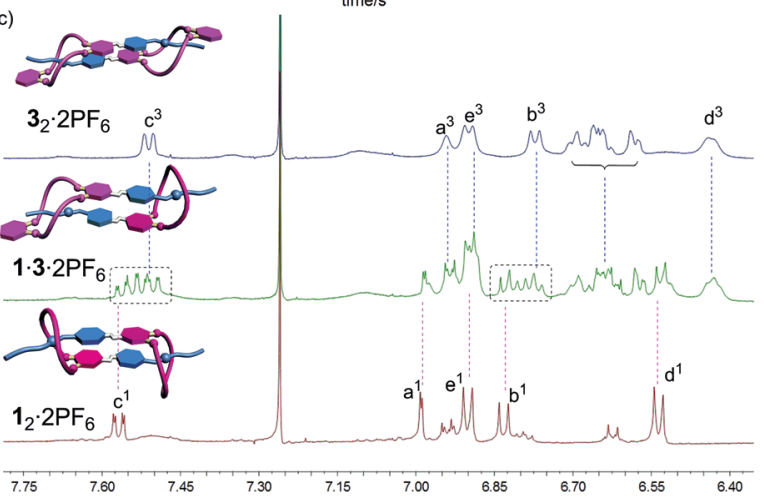

Fig. 6 (a) Partial ESI mass spectrum of a $1: 1$ mixture of $1_{2} \cdot 2 \mathrm{PF}_{6}$ and $3_{2} \cdot 2 \mathrm{PF}_{6}\left(100 \mu \mathrm{M}\right.$ for each monomer) in $\mathrm{CHCl}_{3}-\mathrm{CH}_{3} \mathrm{CN}(2: 1)$ recorded after $3.5 \mathrm{~h}$ of equilibration time. (b) The equilibration can be followed over time and occurs on a minute time scale. (c) Partial ${ }^{1} \mathrm{H}$ NMR spectra (500 MHz, $\mathrm{CDCl}_{3}-\mathrm{CD}_{3} \mathrm{CN}=2: 1,10.0 \mathrm{mM}, 298 \mathrm{~K}$ ) of $1_{2} \cdot 2 \mathrm{PF}_{6}$ (bottom row), an equimolar mixture of $1_{2} \cdot 2 \mathrm{PF}_{6}$ and $3_{2} \cdot 2 \mathrm{PF}_{6}$ (centre), and $3_{2} \cdot 2 \mathrm{PF}_{6}$ (top row).

exclusively. A look at the corresponding ESI mass spectrum (Fig. 7a) confirms the heterodimer to be the most prominent species in the sample solution which again forms on a minute time scale (Fig. 7b). As time passed by, we could see the decrease of the signal of $2^{+}$from $50 \%$ to less than $6 \%$ and the gradual increase of the intensity of $[2 \cdot 3]^{2+}$ (ESI $\dagger$ ). Similar ESI mass spectrometric behaviour (higher intensity) were found for $3_{2}{ }^{2+}$ in Fig. 6 and 7, maybe due to its much different desolvation energy from those of other species. Nevertheless, some contribution from $2 \cdot \mathrm{PF}_{6}$ and $3_{2} \cdot 2 \mathrm{PF}_{6}$ is still observed and one would arrive at the conclusion that self-sorting is imperfect.

A closer inspection of the NMR spectra of the individual compounds and the mixture of both, however, reveals that selfsorting is almost complete. The ${ }^{1} \mathrm{H}$ NMR spectrum of the mixture exhibits new sets of signals that are not present in the individual parent compounds. In turn, the signals for $2 \cdot \mathrm{PF}_{6}$ and $3_{2} \cdot 2 \mathrm{PF}_{6}$ are missing in the spectrum of the mixture as seen, for example, for $\mathrm{c}^{3}, \mathrm{k}^{3}$ and $\mathrm{e}^{2}$ (Fig. 7c). Such a divergence of the ESI mass spectrometric and NMR spectroscopic results has been observed earlier for other supramolecular self-sorting complexes. $^{3 d, e}$ As the NMR $(10.0 \mathrm{mM})$ results reflect the
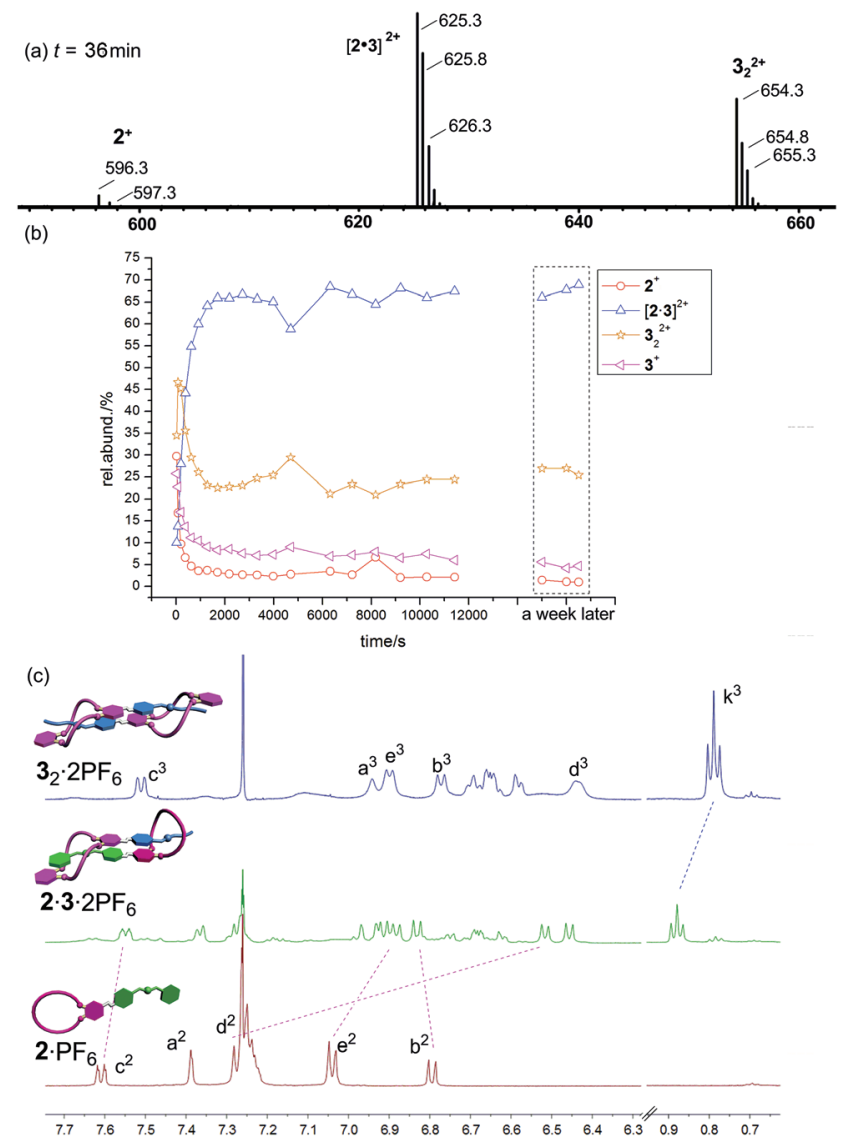

Fig. 7 (a) Partial ESI mass spectrum of a $2: 1$ mixture of $2 \cdot \mathrm{PF}_{6}$ and $32 \cdot 2 \mathrm{PF}_{6}\left(100 \mu \mathrm{M}\right.$ for each monomer) in $\mathrm{CHCl}_{3}-\mathrm{CH}_{3} \mathrm{CN}(2: 1)$ recorded after $36 \mathrm{~min}$ of equilibration time. (b) The self-sorting can be followed over time and occurs on a minute time scale. (c) Partial ${ }^{1} \mathrm{H}$ NMR spectra (500 MHz, $\mathrm{CDCl}_{3}-\mathrm{CD}_{3} \mathrm{CN}=2: 1,10.0 \mathrm{mM}, 298 \mathrm{~K}$ ) of $2 \cdot \mathrm{PF}_{6}$ (bottom row), a $2: 1$ mixture of $2 \cdot \mathrm{PF}_{6}$ and $3_{2} \cdot 2 \mathrm{PF}_{6}$ (centre), and $3_{2} \cdot 2 \mathrm{PF}_{6}$ (top row).

solution situation more directly than ESI mass spectrometry $(100 \mu \mathrm{M})$, we can therefore conclude that self-sorting quite nicely works for the $2 \cdot \mathrm{PF}_{6} / 3_{2} \cdot 2 \mathrm{PF}_{6}$ combination.

\section{Experimental section}

\section{General}

All reagents were commercially available and used as supplied without further purification. Benzo[21]crown-7 carboxylic acid

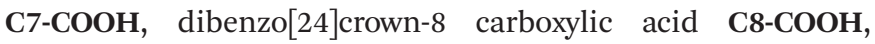
monomer $1 \cdot \mathrm{PF}_{6}$, and axle precursors 5 and 6 were prepared according to literature procedures. ${ }^{13,14}{ }^{1} \mathrm{H}$ NMR spectra were collected on a temperature-controlled $500 \mathrm{MHz}$ Bruker AVANCE DMX-500 spectrometer with the deuterated solvent as the lock and the residual undeuterated solvent or TMS as the internal reference. Chemical shifts are reported in ppm and coupling constants in hertz $(\mathrm{Hz}),{ }^{13} \mathrm{C}$ NMR spectra were recorded on a Bruker AVANCE DMX-500 spectrometer. The crystal structure data were collected on an Oxford Diffraction Xcalibur Gemini Ultra diffractometer with an Atlas detector. 
The electrospray-ionization Fourier-transform ion-cyclotronresonance (ESI-FTICR) mass spectrometric experiments were performed with a Varian/IonSpec QFT-7 FTICR mass spectrometer equipped with a superconducting 7 Tesla magnet and a Micromass Z-spray ESI ion source utilizing a stainless steel capillary with a $0.65 \mathrm{~mm}$ inner diameter. The solutions of samples $\left(100 \mu \mathrm{M}\right.$ in $\mathrm{CHCl}_{3}-\mathrm{CH}_{3} \mathrm{CN} 2: 1$ were introduced into the source with a syringe pump (Harvard Apparatus) at a flow

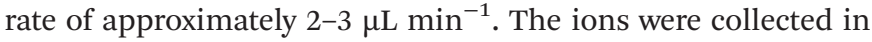
the instrument's accumulation hexapole long enough to obtain useful signal-to-noise ratios, introduced into the FTICR analyzer cell, which was operated at pressures below $10^{-9}$ mbar, and detected by a standard excitation and detection sequence. The ionization voltage was set to $3000-3500 \mathrm{~V}$, source and probe temperature were $40{ }^{\circ} \mathrm{C}$. The sample cone voltage was set to $25-30 \mathrm{~V}$.

\section{Syntheses}

Monomer 2.PF 6 . A solution of C7-COOH $(170 \mathrm{mg}$, $0.42 \mathrm{mmol}$ ), 5 (133 mg, $0.42 \mathrm{mmol}$ ), EDC (178 mg, $0.90 \mathrm{mmol}$ ) and DMAP (24 mg, $0.20 \mathrm{mmol})$ in dichloromethane $(10 \mathrm{~mL})$ was stirred for $24 \mathrm{~h}$ at room temperature. The solvent was removed to give a crude product, which was subjected to column chromatography (ethyl acetate) to obtain the pure product. The product was dissolved in 10\% HCl-ethyl acetate $(10 \mathrm{~mL})$ and stirred overnight. The white solid was filtered, washed with ethyl acetate thoroughly, and dissolved in warm deionized water $(20 \mathrm{~mL})$. A saturated aqueous solution of $\mathrm{NH}_{4} \mathrm{PF}_{6}$ was added to afford a white precipitate, which was filtered off and washed with deionized water to yield monomer $2 \cdot \mathrm{PF}_{6}$ as a white solid (188 mg, 60\%), mp 117-120 ${ }^{\circ} \mathrm{C} .{ }^{1} \mathrm{H}$ NMR (500 MHz, DMSO- $\left.d_{6}, 295 \mathrm{~K}\right) \delta(\mathrm{ppm}): 7.76(\mathrm{~d}, J=8.5 \mathrm{~Hz}, 1 \mathrm{H})$, 7.60-7.52 (m, 3H), 7.51-7.37 (m, 5H), 7.33 (d, $J=8.3 \mathrm{~Hz}, 2 \mathrm{H})$, $7.17(\mathrm{~d}, J=8.3 \mathrm{~Hz}, 1 \mathrm{H}), 4.24-4.20(\mathrm{~s}, 2 \mathrm{H}), 4.20-4.15(\mathrm{~s}, 2 \mathrm{H})$, 4.15-4.07 (m, 4H), 3.82-3.75 (m, 4H), 3.65-3.59 (m, 4H), 3.59-3.54 (m, 4H), 3.54-3.48 (m, 8H). ${ }^{13} \mathrm{C}$ NMR (125 MHz, acetone- $\left.d_{6}, 295 \mathrm{~K}\right) \delta$ (ppm): 164.11, 153.05, 152.08, 148.06, 131.69, 131.48, 130.05, 129.45, 129.24, 129.01, 124.60, 122.52, 121.82, 113.59, 112.06, 70.07, 69.82, 69.65, 69.33, 69.19, 67.96, 51.93, 51.29. HRESIMS: $m / z$ calcd for $\left[\mathrm{M}-\mathrm{PF}_{6}\right]^{+} \mathrm{C}_{30} \mathrm{H}_{44} \mathrm{NO}_{9}$, 562.3011; found 562.3032, error: 3.7 ppm.

Monomer $3 \cdot \mathbf{P F}_{\mathbf{6}}$. A solution of C8-COOH (243 $\mathrm{mg}$, $0.49 \mathrm{mmol}$ ), 6 (138 mg, $0.49 \mathrm{mmol}$ ), EDC (192 mg, $1.00 \mathrm{mmol}$ ) and DMAP (24 mg, $0.20 \mathrm{mmol})$ in dichloromethane $(20 \mathrm{~mL})$ was stirred for $24 \mathrm{~h}$ at room temperature. After workup as described above for $2 \cdot \mathrm{PF}_{6}$, monomer $3 \cdot \mathrm{PF}_{6}$ was obtained as a white solid (350 mg, 89\%), mp 120-122 ${ }^{\circ} \mathrm{C} .{ }^{1} \mathrm{H} \quad \mathrm{NMR}$ (500 MHz, DMSO- $\left.d_{6}, 295 \mathrm{~K}\right) \delta(\mathrm{ppm}): 8.75-8.63$ (br, 2H), 7.75 $(\mathrm{d}, J=8.6 \mathrm{~Hz}, 1 \mathrm{H}), 7.60-7.54(\mathrm{~m}, 3 \mathrm{H}), 7.35(\mathrm{~d}, J=8.1 \mathrm{~Hz}, 2 \mathrm{H})$, $7.15(\mathrm{~d}, J=8.6 \mathrm{~Hz}, 1 \mathrm{H}), 6.98-6.83(\mathrm{~m}, 4 \mathrm{H}), 4.23-4.13(\mathrm{~m}, 6 \mathrm{H})$, 4.09-4.03 (m, 4H), 3.84-3.74 (m, 8H), 3.71-3.64 (m, 8H), 2.99-2.90 (m, 2H), 1.65-1.54 (m, 2H), 1.39-1.29 (m, 2H), 0.90 $(\mathrm{t}, J=7.3 \mathrm{~Hz}, 3 \mathrm{H}) .{ }^{13} \mathrm{C} \mathrm{NMR}\left(125 \mathrm{MHz}, \mathrm{DMSO}-d_{6}, 295 \mathrm{~K}\right)$ $\delta$ (ppm): 164.63, 153.82, 151.63, 148.87, 148.45, 131.73, 130.07, $124.86,122.82,121.58,121.18,114.45,113.01,71.02,70.95$, $70.91,70.88,69.63,69.60,69.47,69.31,69.14,49.95,46.95$,
27.88, 19.72, 13.94. HRESIMS: $m / z$ calcd for $[\mathrm{M}-\mathrm{PF} 6]+$ $\mathrm{C}_{36} \mathrm{H}_{48} \mathrm{NO}_{10}, 654.3273$; found 654.3243, error $4.6 \mathrm{ppm}$.

Monomer $4 \cdot \mathbf{P F}_{6}$. A solution of $\mathbf{C 8}-\mathbf{C O O H}(247 \mathrm{mg}$, $0.50 \mathrm{mmol}$ ), 5 (157 mg, $0.50 \mathrm{mmol}$ ), EDC (192 mg, $1.00 \mathrm{mmol})$ and DMAP (24 mg, $0.20 \mathrm{mmol})$ in dichloromethane $(20 \mathrm{~mL})$ was stirred for $36 \mathrm{~h}$ at room temperature. After the workup as described above, monomer 4.PF6 was obtained as a white solid (300 mg, 72\%), mp 103-105 ${ }^{\circ} \mathrm{C}$. 1H NMR (500 MHz, DMSO-d6, $295 \mathrm{~K}) \delta$ (ppm): 9.27-9.14 (br, 2H), 7.74 (d, J = 8.5 Hz, 1H), 7.59-7.53 (m, 3H), 7.53-7.39 (m, 5H), 7.34 (d, $J=8.0 \mathrm{~Hz}$, $2 \mathrm{H}), 7.13(\mathrm{~d}, J=7.9 \mathrm{~Hz}, 1 \mathrm{H}), 6.96-6.82(\mathrm{~m}, 4 \mathrm{H}), 4.27-4.09$ $(\mathrm{m}, 8 \mathrm{H}), 4.08-4.00(\mathrm{~m}, 4 \mathrm{H}), 3.84-3.72(\mathrm{~m}, 8 \mathrm{H}), 3.71-3.60(\mathrm{~m}$, $8 \mathrm{H}) .{ }^{13} \mathrm{C}$ NMR (125 MHz, DMSO- $\left.d_{6}, 295 \mathrm{~K}\right) \delta$ (ppm): 164.66, 153.84, 151.68, 148.89, 148.47, 132.31, 131.89, 130.46, 129.92, $129.55,129.21,124.88,122.80,121.61,121.21,114.46,113.03$, 71.05, 70.98, 70.94, 70.91, 69.66, 69.63, 69.49, 69.34, 69.15, 50.73, 50.11. HRESIMS: $m / z$ calcd for $\left[\mathrm{M}-\mathrm{PF}_{6}\right]^{+} \mathrm{C}_{39} \mathrm{H}_{46} \mathrm{NO}_{10}$, 688.3116; found 688.3108, error $1.2 \mathrm{ppm}$.

\section{X-ray crystallographic data}

Solid-state structure of $\mathbf{3}_{\mathbf{2}} \cdot \mathbf{2 P F}_{\mathbf{6}}$. Block, colourless, $\mathrm{C}_{36} \mathrm{H}_{48} \mathrm{~F}_{6} \mathrm{NO}_{10} \mathrm{P}$, FW 799.73, triclinic, space group $P \overline{1}, a=$

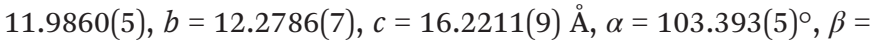
$110.555(5)^{\circ}, \gamma=92.801(4)^{\circ}, V=2152.18(19) \AA^{3}, Z=2, D_{\mathrm{c}}=$ $1.234 \mathrm{~g} \mathrm{~cm}^{-3}, T=140(2) \mathrm{K}, \mu=0.140 \mathrm{~mm}^{-1}, 7859$ measured reflections, 3825 independent reflections, 609 parameters, 1729 restraints, $F(000)=840, R_{1}=0.1665, \mathrm{w} R_{2}=0.3278$ (all data), $R_{1}=0.0970, \mathrm{w} R_{2}=0.2891[I>2 \sigma(I)]$, max. residual density 0.386 e $\AA^{-3}$, and goodness-of-fit $\left(F^{2}\right)=1.090$. CCDC number: 952285.

Solid-state structure of $\mathbf{4}_{2} \cdot \mathbf{P P F}_{\mathbf{6}}$. Block, colourless, $\mathrm{C}_{39} \mathrm{H}_{46} \mathrm{~F}_{6} \mathrm{NO}_{10} \mathrm{P}$, FW 833.73, triclinic, space group $P 2{ }_{1} / n, a=$ 10.4663(3), $b=42.4866(16), c=25.4339(9) \AA, \alpha=90.00^{\circ}, \beta=$ $113.902(3)^{\circ}, \gamma=90.00^{\circ}, V=10339.9(6) \AA^{3}, Z=4, D_{\mathrm{c}}=1.070 \mathrm{~g} \mathrm{~cm}^{-3}$, $T=140(2) \mathrm{K}, \mu=1.054 \mathrm{~mm}^{-1}, 13857$ measured reflections, 8431 independent reflections, 1040 parameters, 126 restraints, $F(000)=3480, R_{1}=0.1859, \mathrm{w} R_{2}=0.4125$ (all data), $R_{1}=0.1501$,

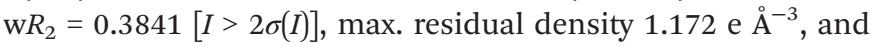
goodness-of-fit $\left(F^{2}\right)=1.342$. CCDC number: 981643 .

\section{Conclusions}

The results obtained in this study confirm the expected selfsorting behaviour of daisy chain monomers $1 \cdot \mathrm{PF}_{6}-\mathbf{4} \cdot \mathrm{PF}_{6}$. While the pairs $\mathbf{1}_{2} \cdot 2 \mathrm{PF}_{6} / \mathbf{4}_{2} \cdot 2 \mathrm{PF}_{6}$ and $2 \cdot \mathrm{PF}_{6} / \mathbf{4}_{2} \cdot 2 \mathrm{PF}_{6}$ do not form heterodimeric daisy chains, $\mathbf{1}_{2} \cdot 2 \mathrm{PF}_{6}$ and $\mathbf{3}_{2} \cdot 2 \mathrm{PF}_{6}$ yield a more or less statistical mixture. The $2 \cdot \mathrm{PF}_{6} / \mathbf{3}_{2} \cdot 2 \mathrm{PF}_{6}$ pair instead forms almost exclusively the heterodimeric daisy chain. The present study thus provides evidence that hetero-[c2]daisy chain pseudorotaxanes can be programmed based on the appropriate choice of orthogonal binding motifs. Both motifs used here are very similar and the self-sorting is based on the size complementarity of crown ether size and ammonium axle width. 
It is, however, this similarity of the two binding motifs which also poses difficulties in the analysis of the solution situation and points to the limits of current routine characterization methods. While X-ray crystallography and NMR experiments are quite straightforward, when it comes to the characterization of the monomers and homodimers, the determination of solution concentrations in mixtures of them is not trivial - even though the molecules under study are structurally not very complicated.

Finally, a combination of ESI mass spectrometry and NMR spectroscopy provides semi-quantitative insight into the selfsorting behaviour as well as a rough estimate on the equilibration time scale. Nevertheless, to know the self-sorting behaviour is a key issue for future studies. For example, $2 \cdot \mathrm{PF}_{6}$ and $3 \cdot \mathrm{PF}_{6}$ can now be equipped with two different functional groups. They can then be brought into proximity to each other, when the heterodimer daisy chain forms - thus providing complexes with two functionalities which might be capable of cooperating with each other e.g. in organocatalysis. The two point attachment between the two monomers provides the basis for better geometrical control over the complex formed than a single-site recognition between the two partners. Furthermore, the exclusive formation of the heterodimer maximizes the concentration of complexes that bear both functional groups and therefore maximizes complex activity. The use of the crown ether/ammonium ion binding motifs renders the complexes switchable by (de)protonation. Consequently, the cooperation of the two functional groups could be switched on and off.

\section{Acknowledgements}

F.H. thanks the financial support from the National Basic Research Program (2013CB834502) and the National Natural Science Foundation of China (21125417). C.A.S. greatly appreciates funding by the Deutsche Forschungsgemeinschaft (SFB 765). We thank Dr Henrik Winkler for orienting measurements. B.Z. thanks the Center for International Cooperation of Freie Universität Berlin for a Ph.D. exchange fellowship.

\section{Notes and references}

1 G. M. Whitesides, J. P. Mathias and C. T. Seto, Science, 1991, 254, 1312-1319.

2 For reviews, see: (a) M. M. Safont-Sempere, G. Fernández and F. Würthner, Chem. Rev., 2011, 111, 5784-5814; (b) M. L. Saha and M. Schmittel, Org. Biomol. Chem., 2012, 10, 4651-4684.

3 Selected examples: (a) Y. Ma, S. V. Kolotuchin and S. C. Zimmerman, J. Am. Chem. Soc., 2002, 124, 1375713769; (b) A. Wu and L. Isaacs, J. Am. Chem. Soc., 2003, 125, 4831-4835; (c) E. S. Barrett, T. J. Dale and J. Rebek Jr., J. Am. Chem. Soc., 2008, 130, 2344-2350; (d) Y. Rudzevich, V. Rudzevich, F. Klautzsch, C. A. Schalley and V. Böhmer,
Angew. Chem., Int. Ed., 2009, 48, 3867-3871; (e) C. Talotta, C. Gaeta, Z. Qi, C. A. Schalley and P. Neri, Angew. Chem., Int. Ed., 2013, 52, 7437-7441.

4 Selected examples: (a) P. N. Taylor and H. L. Anderson, J. Am. Chem. Soc., 1999, 121, 11538-11545; (b) J.-M. Lehn, Science, 2002, 295, 2400-2403; (c) I.-W. Hwang, T. Kamada, T. K. Ahn, D. M. Ko, T. Nakamura, A. Tsuda, A. Osuka and D. Kim, J. Am. Chem. Soc., 2004, 126, 16187-16198; (d) K.-W. Chi, C. Addicott, A. M. Arif and P. J. Stang, J. Am. Chem. Soc., 2004, 126, 16569-16574; (e) B. H. Northrop, Y.-R. Zheng, K.-W. Chi and P. J. Stang, Acc. Chem. Res., 2009, 42, 1554-1563; ( $f$ ) Y. R. Zheng; H. B. Yang, K. Ghosh, L. Zhao and P. J. Stang, Chem. - Eur. J., 2009, 15, 72037214; $(g)$ S. Ulrich and J.-M. Lehn, J. Am. Chem. Soc., 2009, 131, 5546-5549; (h) S. Ulrich and J.-M. Lehn, Chem. - Eur. J., 2009, 15, 5640-5645; (i) K. Mahata and M. Schmittel, J. Am. Chem. Soc., 2009, 131, 16544-16554; (j) T. Murase, S. Horiuchi and M. Fujita, J. Am. Chem. Soc., 2010, 132, 7864-7865; (k) Y. Yamauchi, M. Yoshizawa, M. Akita and M. Fujita, J. Am. Chem. Soc., 2010, 132, 960-966; (l) K. Mahata, M. L. Saha and M. Schmittel, J. Am. Chem. Soc., 2010, 132, 15933-15935; ( $m$ ) M. Schmittel and K. Mahata, Chem. Commun., 2010, 46, 4163-4165; (n) M. M. J. Smulders, A. Jiménez and J. R. Nitschke, Angew. Chem., Int. Ed., 2012, 51, 6681-6685; (o) A. S. Singh and S.-S. Sun, Chem. Commun., 2012, 48, 7392-7394; (p) M. L. Saha, S. Pramanik and M. Schmittel, Chem. Commun., 2012, 48, 9459-9461.

5 Selected examples: (a) A. D. Shaller, W. Wang, H. Gan and A. D. Q. Li, Angew. Chem., Int. Ed., 2008, 47, 7705-7709; (b) S. Ghosh, A. Wu, J. C. Fettinger, P. Y. Zavalij and L. Isaacs, J. Org. Chem., 2008, 73, 5915-5925; (c) S. Ghosh, X.-Q. Li, V. Stepanenko and F. Würthner, Chem. - Eur. J., 2008, 14, 11343-11357; (d) M. M. Safont-Sempere, P. Osswald, M. Stolte, M. Grüne, M. Renz, M. Kaupp, K. Radacki, H. Braunschweig and F. Würthner, J. Am. Chem. Soc., 2011, 133, 9580-9591.

6 Selected examples: (a) N. Tomimasu, A. Kanaya, Y. Takashima, H. Yamaguchi and A. Harada, J. Am. Chem. Soc., 2009, 131, 12339-12343; (b) W. Jiang, Q. Wang, I. Linder, F. Klautzsch and C. A. Schalley, Chem. - Eur. J., 2011, 17, 2344-2348.

7 (a) P. Mukhopadhyay, P. Y. Zavalij and L. Isaacs, J. Am. Chem. Soc., 2006, 128, 14093-14102; (b) P. Mukhopadhyay, A. Wu and L. Isaacs, J. Org. Chem., 2004, 69, 6157-6164.

8 (a) P. R. Ashton, E. J. T. Chrystal, P. T. Glink, S. Menzer, C. Schiavo, N. Spencer, J. F. Stoddart, P. A. Tasker, A. J. P. White and D. J. Williams, Chem. - Eur. J., 1996, 2, 709-728; (b) N. Yamaguchi, L. M. Hamilton and H. W. Gibson, Angew. Chem., Int. Ed., 1998, 37, 3275-3279; (c) P. R. Ashton, I. Baxter, M. C. T. Fyfe, F. M. Raymo, N. Spencer, J. F. Stoddart, A. J. P. White and D. J. Williams, J. Am. Chem. Soc., 1998, 120, 2297-2307; (d) T. Clifford, A. Abushamleh and D. H. Busch, Proc. Natl. Acad. Sci. U. S. A., 2002, 99, 4830-4836; (e) F. Huang, K. A. Switek, L. N. Zakharov, F. R. Fronczek, C. Slebodnick, M. Lam, 
J. A. Golen, W. S. Bryant, P. E. Mason, A. L. Rheingold, M. Ashraf-Khorassani and H. W. Gibson, J. Org. Chem., 2005, 70, 3231-3241; (f) Z. Niu, F. Huang and H. W. Gibson, J. Am. Chem. Soc., 2011, 133, 2836-2839.

9 (a) F. Wang, C. Han, C. He, Q. Zhou, J. Zhang, C. Wang, N. Li and F. Huang, J. Am. Chem. Soc., 2008, 130, 1125411255; (b) W. Jiang, H. D. F. Winkler and C. A. Schalley, J. Am. Chem. Soc., 2008, 130, 13852-13853; (c) W. Jiang and C. A. Schalley, Proc. Natl. Acad. Sci. U. S. A., 2009, 106, 10425-10429; (d) F. Wang, B. Zheng, K. Zhu, Q. Zhou, C. Zhai, S. Li, N. Li and F. Huang, Chem. Commun., 2009, 4375-4377; (e) W. Jiang, A. Schäfer, P. C. Mohr and C. A. Schalley, J. Am. Chem. Soc., 2010, 132, 2309-2320; (f) W. Jiang and C. A. Schalley, J. Mass Spectrom., 2010, 45, 788-798; (g) W. Jiang, D. Sattler, K. Rissanen and C. A. Schalley, Org. Lett., 2011, 13, 4502-4505; (h) W. Jiang, K. Nowosinski, N. L. Löw, E. V. Dzyuba, F. Klautzsch, A. Schäfer, J. Huuskonen, K. Rissanen and C. A. Schalley, J. Am. Chem. Soc., 2012, 134, 1860-1868; (i) S. Dong, B. Zheng, M. Zhang, X. Yan, X. Ding, Y. Yu and F. Huang, Macromolecules, 2012, 45, 9070-9075; (j) S. Dong, X. Yan, B. Zheng, J. Chen, X. Ding, Y. Yu, D. Xu, M. Zhang and F. Huang, Chem. - Eur. J., 2012, 18, 4195-4199.

10 (a) P. R. Ashton, P. J. Campbell, P. T. Glink, D. Philp, N. Spencer, J. F. Stoddart, E. J. T. Chrystal, S. Menzer, D. J. Williams and P. A. Tasker, Angew. Chem., Int. Ed. Engl., 1995, 34, 1865-1869; (b) C. Zhang, S. Li, J. Zhang, K. Zhu, N. Li and F. Huang, Org. Lett., 2007, 9, 5553-5556.

11 Reviews: (a) L. Fang, M. A. Olson, D. Benitez, E. Tkatchouk, W. A. Goddard III and J. F. Stoddart, Chem. Soc. Rev., 2010, 39, 17-29; (b) J. Rotzler and M. Mayor, Chem. Soc. Rev., 2013, 42, 44-62; (c) B. Zheng, F. Wang, S. Dong and F. Huang, Chem. Soc. Rev., 2012, 41, 1621-1636. Selected examples: (d) P. R. Ashton, I. Baxter, S. J. Cantrill, M. C. T. Fyfe, P. T. Glink, J. F. Stoddart, A. J. P. White and D. J. Williams, Angew. Chem., Int. Ed., 1998, 37, 1294-1297; (e) S. J. Cantrill, G. J. Youn, J. F. Stoddart and D. J. Williams, J. Org. Chem., 2001, 66, 6857-6872; (f) D. G. Amirsakis, A. M. Elizarov, M. A. Garcia-Garibay, P. T. Glink, J. F. Stoddart, A. J. P. White and D. J. Williams, Angew. Chem., Int. Ed., 2003, 42, 1126-1132; (g) M. P. L. Werts,
M. van den Boogaard, G. M. Tsivgoulis and G. Hadziioannou, Macromolecules, 2003, 36, 7004-7013; (h) H. W. Gibson, N. Yamaguchi, Z. Niu, J. W. Jones, C. Slebodnick, A. L. Rheingold and L. N. Zakharov, J. Polym. Sci., Part A: Polym. Chem., 2010, 48, 975-985; (i) L. Cao and L. Isaacs, Org. Lett., 2012, 14, 3072-3075; (j) Z. Zhang, G. Yu, C. Han, J. Liu, X. Ding, Y. Yu and F. Huang, Org. Lett., 2011, 13, 4818-4821; (k) Z. Zhang, C. Han, G. Yu and F. Huang, Chem. Sci., 2012, 3, 3026-3031.

12 Review: (a) J.-P. Collin, C. Dietrich-Buchecker, P. Gaviña, M. C. Jimenez-Molero and J.-P. Sauvage, Acc. Chem. Res., 2001, 34, 477-487; examples: (b) C. Romuald, E. Busseron and F. Coutrot, J. Org. Chem., 2010, 75, 6516-6531; (c) G. Du, E. Moulin, N. Jouault, E. Buhler and N. Giuseppone, Angew. Chem., Int. Ed., 2012, 51, 1250412508; (d) X. Yan, B. Zheng and F. Huang, Polym. Chem., 2013, 4, 2395-2399.

13 B. Zheng, M. Zhang, S. Dong, J. Liu and F. Huang, Org. Lett., 2012, 14, 306-309.

14 (a) D.-J. Feng, X.-Q. Li, X.-Z. Wang, X.-K. Jiang and Z.-T. Li, Tetrahedron, 2004, 60, 6137-6144; (b) L. Wu, Y.-M. He and Q.-H. Fan, Adv. Synth. Catal., 2011, 353, 2915-2919.

15 S. Di Stefano, J. Phys. Org. Chem., 2010, 23, 797-805.

16 E. Leize, A. Jaffrezic and A. Van Dorsselaer, J. Mass Spectrom., 1996, 31, 537-544.

17 For reviews on multivalency, see: (a) M. Mammen, S. K. Choi and G. M. Whitesides, Angew. Chem., Int. Ed., 1998, 37, 2754-2794; (b) A. Mulder, J. Huskens and D. N. Reinhoudt, Org. Biomol. Chem., 2004, 2, 3409-3424; (c) J. D. Badjic, A. Nelson, S. J. Cantrill, W. B. Turnbull and J. F. Stoddart, Acc. Chem. Res., 2005, 38, 723-732; (d) C. Fasting, C. A. Schalley, M. Weber, O. Seitz, S. Hecht, B. Koksch, J. Dernedde, C. Graf, E.-W. Knapp and R. Haag, Angew. Chem., Int. Ed., 2012, 51, 10472-10498. For reviews on the thermodynamic analysis of chelate cooperativity in supramolecular complexes, see: (e) G. Ercolani, C. Piguet, M. Borkovec and J. Hamacek, J. Phys. Chem. B, 2007, 111, 12195-12203; $(f)$ C. A. Hunter and H. L. Anderson, Angew. Chem., Int. Ed., 2009, 48, 7488-7499; $(g)$ G. Ercolani and L. Schiaffino, Angew. Chem., Int. Ed., 2011, 50, 1762-1768. 